Journal of Advanced Research in Fluid Mechanics and Thermal Sciences

Journal homepage: www.akademiabaru.com/arfmts.html ISSN: 2289-7879

\title{
Dual Solutions of MHD Stagnation Slip Flow Past a Permeable Plate
}

\author{
Mohamad Mustaqim Junoh ${ }^{1,3, *}$, Nursyahanis Abdullah², Fadzilah Md Ali ${ }^{2,3}$ \\ Faculty of Computer and Mathematical Sciences, Universiti Teknologi MARA Cawangan Johor, 85000 Segamat, Johor, Malaysia \\ Department of Mathematics, Faculty of Science, Universiti Putra Malaysia, 43400 Serdang, Selangor, Malaysia \\ Institute for Mathematical Research, Universiti Putra Malaysia, 43400 Serdang, Selangor, Malaysia
}

\section{ARTICLE INFO}

\section{Article history:}

Received 29 October 2020

Received in revised form 1 January 2021

Accepted 9 January 2021

Available online 5 February 2021

Keywords:

Dual solutions; MHD; slip flow;

stagnation point; suction

\section{ABSTRACT}

In this paper, dual solution to the problem of steady laminar magnetohydrodynamics boundary layer stagnation slip flow of the electrically conducting fluid over a permeable plate with suction effect is performed. The governing partial differential equations of the boundary layer are transformed into nonlinear ordinary differential equations via similarity transformations, and then numerically solved using the bvp4c method, which is the integrated algorithm of MATLAB. The effect of magnetic, slip and suction parameters on the skin friction coefficients and the velocity profiles $f^{\prime}(\eta), g(\eta)$ and $h(\eta)$ are presented in graphical form and discussed in detail. Dual solutions have been identified when suction is implied.

\section{Introduction}

The theory of magnetohydrodynamic (MHD) boundary layers plays a momentous role in the recent development of magnetohydrodynamic [1]. Over the last few years, the study of MHD flow and heat transfer near stagnation point has attracted a great deal of interest from researchers due to the effect of the magnetic field on the boundary layer flow [2-8]. Convective boundary layer flow of electrically conductive fluid in the presence of a magnetic field has been the focus of a significant number of investigations due to its fundamental significance in industrial and technical applications, including crystal growth, reactor cooling and metal surface coating. The Lorentz force, which is synonym with magnetic field, is influential and works with the buoyancy force in controlling the flow and temperature fields. The effect of the Lorentz force is known to suppress the convection and an external magnetic field is applied as a control mechanism in material manufacturing industry [9]. The MHD parameter is one of the important parameters by which the cooling rate can be controlled and the product of the desired quality can be achieved [9]. Zhu et al.,

\footnotetext{
* Corresponding author.

E-mail address: mohamadmustaqimjunoh@gmail.com
}

https://doi.org/10.37934/arfmts.80.1.137146 
[10] studied the steady two-dimensional MHD stagnation flow towards a nonlinear stretching surface. The no-slip condition on the solid boundary replaced with partial slip condition. Ellahi et al., [11] investigated the combined effects of magnetohydrodynamic heat transfer flow with the influence of slip over a moving at plate. The effect of entropy generation was also examined. A research done by Nandeppanavar et al., [12] regarding the heat transfer characteristics of the stagnation point flow of MHD flow over a non-linearly moving plate with momentum and thermal slip effects in the presence of non-uniform heat source showed that the non-uniform heat source parameters enhance the temperature distribution.

Stagnation-point flow towards a stretching vertical sheet with slip effects was studied by Zaimi and Ishak [13]. The effects of partial slip on stagnation-point flow and heat transfer due to a stretching vertical sheet were investigated. Zaimi and Ishak [13] found that dual solutions exist in a certain range of buoyancy parameters. Dual solutions for a certain range of shrinking parameter also reported in the study by Bachok et al., [14,15]. Later, Mukhopadhyay [16] described the boundary layer flow and heat transfer towards a porous exponential stretching sheet in the presence of magnetic field. Velocity slip and thermal slip were considered instead of no-slip condition. Khan et al., [17] studied the magnetohydrodynamic boundary layer thermal slip flow by non-linearly stretching cylinder with the effect of suction and radiation. The flow was discussed in the presence of velocity and thermal slip conditions. Lok et al., [18] investigated a steady twodimensional magnetohydrodynamic stagnation point flow with suction towards a shrinking sheet, and found that strong suction is necessary for the multiple solutions to exist. Ishak et al., [19] studied the effect of suction/injection on the laminar mixed convection boundary layer flow over a vertical wall in an incompressible viscous fluid, and observed that dual solutions exist for assisting flow only. The MHD stagnation point flow of a nanofluid over a permeable stretching/shrinking sheet problem has studied by Mansur et al., [20].

Motivated by the above-mentioned literatures, the interest in this current study is to carry out a comprehensive study which will provide dual solutions to the problem considered by Ali et al., [21], with the effect of suction. Many studies on dual solutions have been done by various researchers such as [22-28]. Moreover, no investigation has yet been conducted into this problem. This study also only limited to the problem of the steady laminar boundary layer flow of electrically conducting viscous fluid on the flat plate. Using similarity variables, a nonlinear ordinary differential equations corresponding to the momentum equations is obtained. These equations are solved numerically using bvp4c method. The effects of the magnetic parameter, the velocity slip parameter and the suction parameter on velocity fields are studied and analyzed by graphical aid.

\section{Methodology}

Consider the steady two-dimensional boundary layer flow of a viscous, incompressible and electrically conducting fluid in the presence of an applied magnetic field near the stagnation point on a plane surface, as shown in Figure 1, where the $x$-axis is measured along the plane surface, the $y$-axis is measured in the transverse direction and the $z$-axis is measured in the normal direction to the plane $z=0$. Following Wang [29], it is assumed that the flow takes place in the $x-z$ plane in the region $z>0$. Therefore, all variables are independent of the $y$ coordinate. Further, it is assumed that the plane moves with velocity $U$ in the $x$-direction and with velocity $V$ in the $y$-direction. The external boundary layer flow (inviscid flow) of velocity $u_{e}(x)=a x$, where $a$ is a positive constant, impinges on the plane $z=0$. It is also assumed that a uniform magnetic field of strength $B_{0}$ is applied normal to the plane $z=0$. 


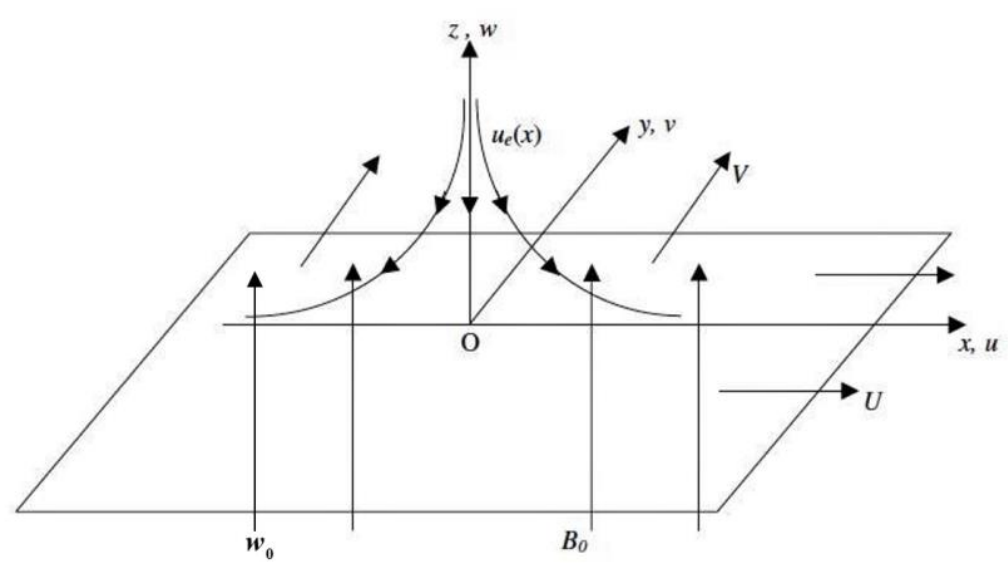

Fig. 1. The physical model with coordinate system of this problem

Under the boundary layer approximations and the assumptions that the viscous dissipation, radiation flux and Joule heating are neglected, the basic equations of the problem under consideration are given by

$\frac{\partial u}{\partial x}+\frac{\partial w}{\partial z}=0$

$u \frac{\partial u}{\partial x}+w \frac{\partial u}{\partial z}=u_{e} \frac{d u_{e}}{d x}+v \frac{\partial^{2} u}{\partial z^{2}}+\frac{\sigma B_{0}{ }^{2}}{\rho}\left(u_{e}-u\right)$

$u \frac{\partial v}{\partial x}+w \frac{\partial v}{\partial z}=v \frac{\partial^{2} v}{\partial z^{2}}-\frac{\sigma B_{0}^{2}}{\rho} v$

$u \frac{\partial w}{\partial x}+w \frac{\partial w}{\partial z}=v \frac{\partial^{2} w}{\partial z^{2}}$

subject to the boundary conditions

$w=w_{0}, \quad u-U=A \rho v \frac{\partial u}{\partial z}, \quad v-V=A \rho v \frac{\partial v}{\partial z}$ at $\quad z=0$,

$u=u_{e}(x)=a x, \quad v=0$ as $z \rightarrow \infty$,

where $u, v$ and $w$ are the velocity components along the $x-, y$-and $z$-axes, respectively, $\sigma$ is the electrical conductivity, $v$ is the kinematic viscosity, $A$ is a slip constant, $a$ is a positive constant, $u_{e}$ is a velocity of the external boundary layer flow, $B_{0}$ is a constant of magnetic field of strength and $\rho$ is the fluid density. Velocity $U$ in the $x$-direction and velocity $V$ in the $y-$ direction. The following similarity transformations has been introduced

$u=a x f^{\prime}(\eta)+U g(\eta), \quad v=V h(\eta), \quad w=-\sqrt{a v} f(\eta), \quad \eta=\sqrt{\frac{a}{v}} z$ 
where $\eta$ is the similarity variable and prime denotes differentiation with respect to $\eta$. Therefore, Eq. (1) is satisfied. Substituting (6) into Eq. (2)-(4), we obtain the following nonlinear ordinary differential equations

$$
\begin{aligned}
& f^{\prime \prime \prime}+f f^{\prime \prime}-\left(f^{\prime}\right)^{2}+1+M\left(1-f^{\prime}\right)=0, \\
& g^{\prime \prime}+f g^{\prime}-f^{\prime} g-M g=0, \\
& h^{\prime \prime}+f h^{\prime}-M h=0,
\end{aligned}
$$

and boundary conditions (6) reduced to

$$
\begin{aligned}
& f(0)=S, \quad f^{\prime}(0)=\lambda f^{\prime \prime}(0), \quad g(0)=1+\lambda g^{\prime}(0), \quad h(0)=1+\lambda h^{\prime}(0) \\
& f^{\prime}(\infty) \rightarrow 1, \quad g(\infty) \rightarrow 0, \quad h(\infty) \rightarrow 0
\end{aligned}
$$

where $M$ is the magnetic parameter, $S$ is the constant mass transfer parameter and $\lambda$ is the slip parameter given by

$$
M=\frac{\sigma B_{0}^{2}}{a \rho}, \quad S=\frac{-w_{0}}{\sqrt{a \nu}}, \quad \lambda=A \rho \sqrt{a \nu} .
$$

The physical quantities of practical interest are the skin frictions $\tau_{w x}$ and $\tau_{w y}$ in the $x-$ and $y-$ directions of the plate, which are defined as

$$
\begin{aligned}
& \tau_{w x}=\mu\left(\frac{\partial u}{\partial z}\right)_{z=0}=\mu \sqrt{\frac{a}{v}}\left[\operatorname{axf} f^{\prime \prime}(0)+U g^{\prime}(0)\right], \\
& \tau_{w y}=\mu\left(\frac{\partial v}{\partial z}\right)_{z=0}=\mu \sqrt{\frac{a}{v}}\left[V h^{\prime}(0)\right] .
\end{aligned}
$$

\section{Results Analysis}

In this present study, we solved numerically the problem of a magnetohydrodynamics (MHD) stagnation slip flow with suction effect. The MHD nonlinear partial differential equations are reduced to nonlinear ordinary differential equations via similarity transformation. The Eq. (7) - (9) subject to boundary conditions (10) have been solved numerically by applying the bvp4c MATLAB solver. The method used in this research is to obtained the skin friction coefficients and the velocity profiles $f^{\prime}(\eta), g(\eta)$ and $h(\eta)$ for various values of magnetic parameter $M$, slip parameter $\lambda$ and suction parameter $S$. Table 1 shows the comparison of the numerical results for the skin friction coefficient $f^{\prime \prime}(0)$ for different values of $M$ with fixed $\lambda=S=0$ with those study by Ariel [30] and Ali et al., [21], in order to compare the accuracy and validity of the method used. The results display that there is a very good agreement between them. 
Figure 2 until 4 show the velocity profiles of $f^{\prime}(\eta), g(\eta)$ and $h(\eta)$ for different values of magnetic parameter $M$ when $S=5.0$ and $\lambda=5.0$, respectively. From Figure 2, we can observe that the velocity profile $f^{\prime}(\eta)$, displays an increasing behaviour for the first and second solutions when the magnetic parameter $M$ increases. The boundary layer thickness for the second solution is larger than the first solution. Next, Figure 3 shows decreasing behaviour for both solutions of velocity profile $g(\eta)$ when the magnetic parameter $M$ is applied. The magnetic parameter gives increment in the boundary layer thickness. Figure 4 shows that the decreasing behaviour for the first and second solutions when the magnetic parameter $M$ increases. This is because with the increase in $M$, Lorentz force increases and it produces more resistance to the flow.

Table 1

Comparison values of the skin friction coefficient $f^{\prime \prime}(0)$ for several values of $M$ at fixed $\lambda=S=0$.

\begin{tabular}{llll}
\hline$M$ & Ariel [30] & Ali et al., [21] & Present \\
\hline 0.05 & 1.25252550 & 1.25253678 & 1.25253674 \\
0.1 & 1.27216910 & 1.27218018 & 1.27218016 \\
0.5 & 1.41975479 & 1.41976289 & 1.41976287 \\
0.1 & 1.58532985 & 1.58533070 & 1.58533068 \\
2.0 & 1.87355121 & 1.87352729 & 1.87352728 \\
\hline
\end{tabular}

Figure 5 until 7 show the velocity profiles $f^{\prime}(\eta), g(\eta)$ and $h(\eta)$ for various values of slip parameter $\lambda$ when $S=5.0$ and $M=0.1$, respectively. In Figure 5, velocity profiles are shown for different values of slip parameter $\lambda$. The velocity profiles show an increasing behaviour for both solutions when the slip parameter increases. The velocity curves show that the rate of transport decreases with the increasing distance $\eta$ from the plate. Figure 6 shows the velocity profiles decreasing behaviour for the first solution as the slip parameter increases. Besides, for the second solution, with the increasing value of the slip parameter $\lambda$, the velocity profiles found to decrease initially but after a certain distance from the plate, it increases with the slip parameter. The velocity curve for both solutions show that the rate of transport decreases with the increasing distance $\eta$ of the plate. In Figure 7, the velocity profiles $h(\eta)$ for the first and the second solutions present some sort of decreasing behaviour with the increase of slip parameter $\lambda$. The velocity curves show that the rate of transport decreases with the increasing distance $\eta$ from the plate.

Figure 8 until 10 show the velocity profiles of $f^{\prime}(\eta), g(\eta)$ and $h(\eta)$ for variation values of suction parameter $S$ when $M=0.1$ and $\lambda=5.0$, respectively. The velocity profiles $f^{\prime}(\eta)$ for different values of suction parameter $S$ are shown in Figure 8. As we can see from Figure 8, the velocity profiles increase as the suction parameter increases in both solutions. It is observed that suction results in an increase in the skin friction coefficient, which led to a reduction in the momentum of the boundary layer thickness, thus enhancing the flow near the surface of the wall. Figure 9 shows that the velocity profile $g(\eta)$ decreases as the suction parameter increases for the first solution. While for the second solution, there is an increasing in the velocity profiles when the suction parameter increases. Therefore, it is observed that with the increasing of suction parameter, the boundary layer thickness increases for the first solution while it decreases for the second solution. Figure 10 displays the decreasing of velocity profiles $h(\eta)$ as the suction $S$ increases for the first and second solutions. It is also found that the boundary layer thickness decreases as the suction parameter increases. 


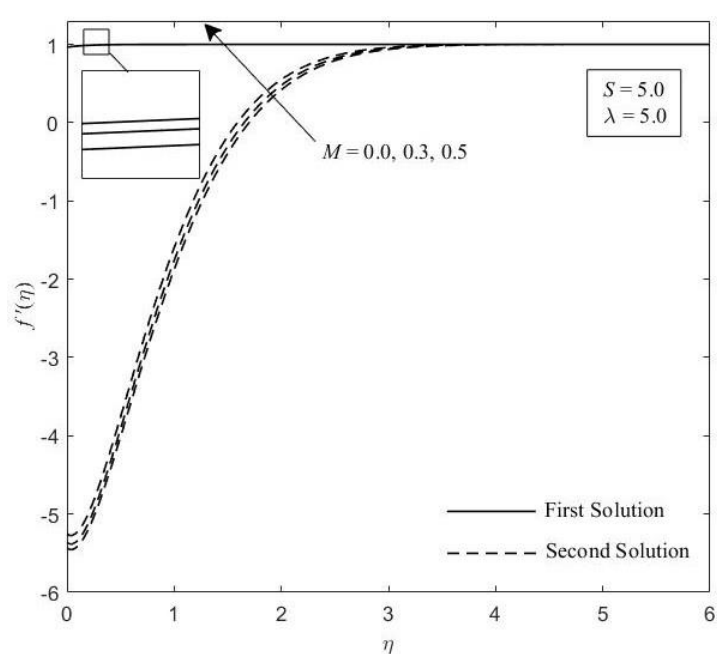

Fig. 2. The velocity profiles $f^{\prime}(\eta)$ for different values of $M$

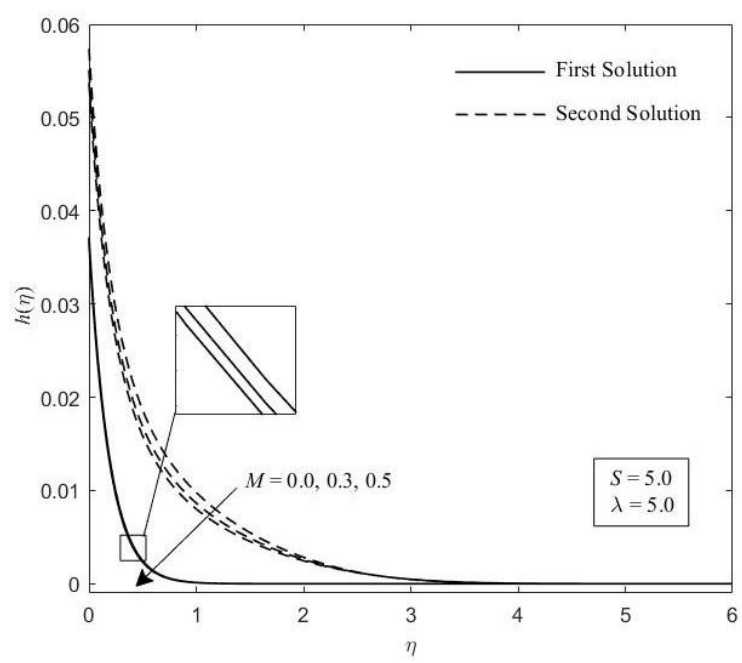

Fig. 4. The velocity profiles $h(\eta)$ for different values of $M$

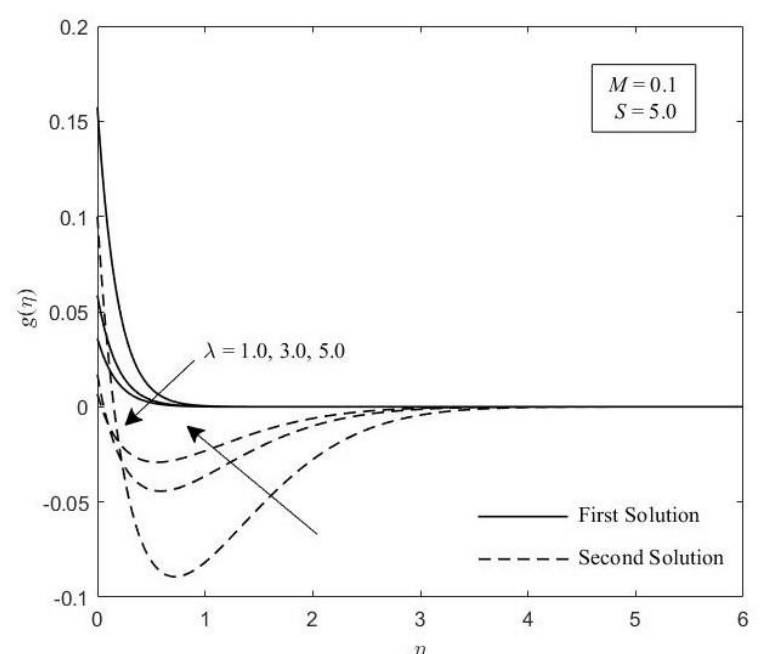

Fig. 6. The velocity profiles $g(\eta)$ for different values of $\lambda$

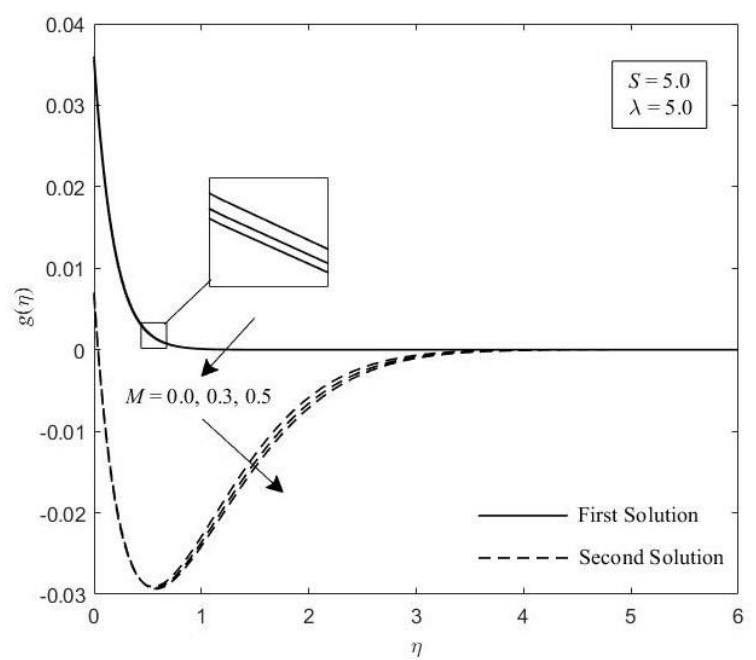

Fig. 3. The velocity profiles $g(\eta)$ for different values of $M$

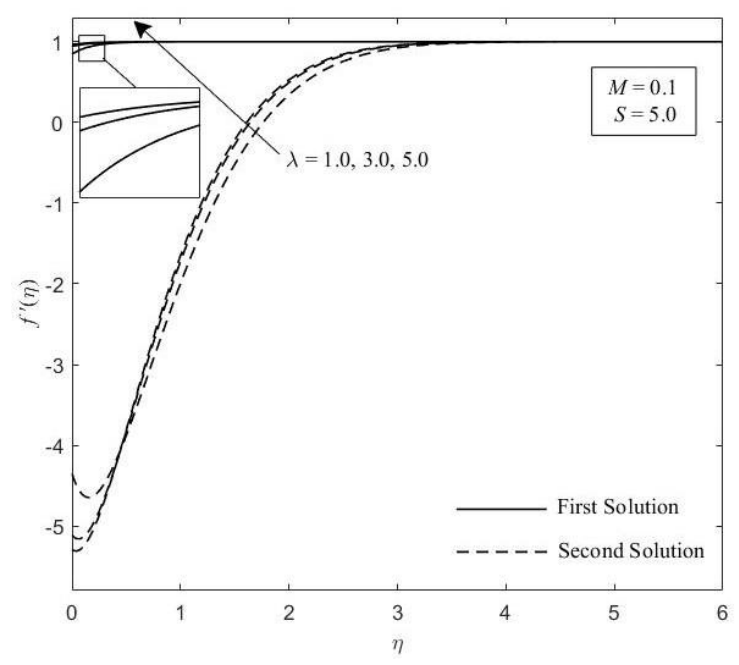

Fig. 5. The velocity profiles $f^{\prime}(\eta)$ for different values of $\lambda$

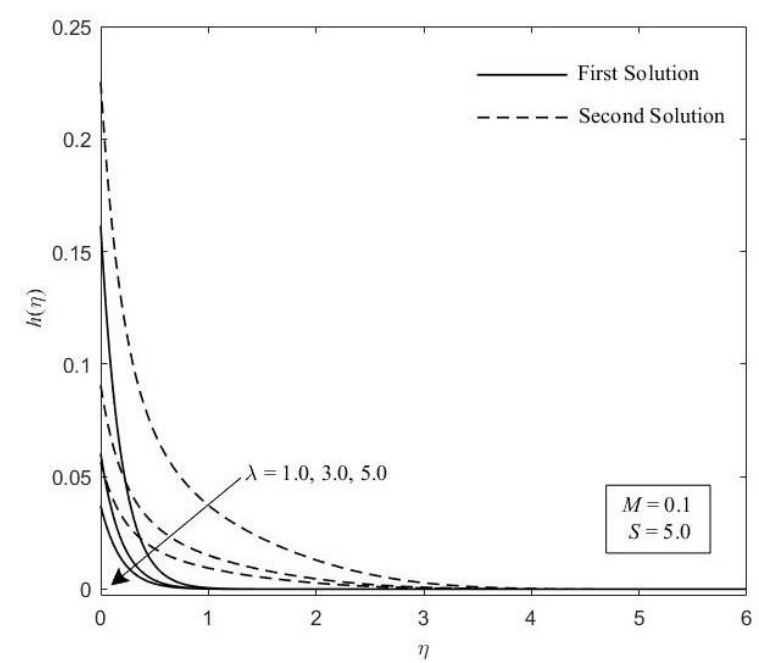

Fig. 7. The velocity profiles $h(\eta)$ for different values of $\lambda$ 


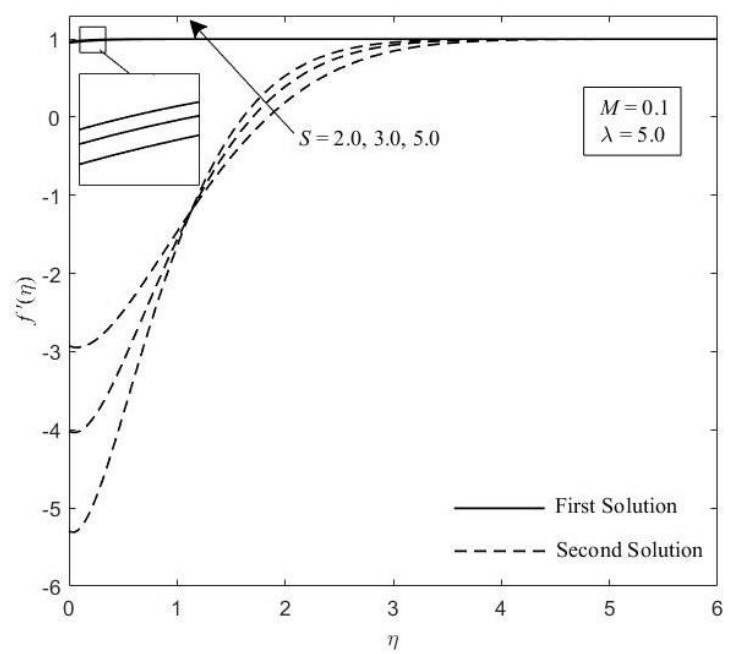

Fig. 8. The velocity profiles $f^{\prime}(\eta)$ for different values of $S$

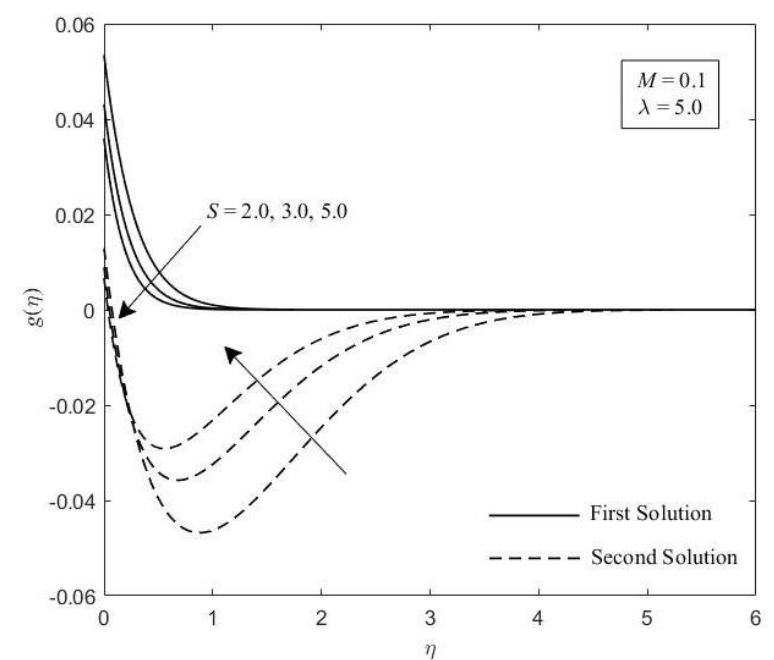

Fig. 9. The velocity profiles $g(\eta)$ for different values of $S$

As we have seen in Figure 2 until 9, all these profiles met the boundary conditions (10), thereby promoting the validity of the results obtained and the existence of non-unique solution (dual solutions) are clearly demonstrated in this study. Figure 11 until 13 depict the dual solutions for the physical quantities of interest, which are the skin friction coefficient $f^{\prime \prime}(0), g^{\prime}(0)$ and $h^{\prime}(0)$ against $S$ with the influence of $M$ for a fixed $\lambda=3$.0. From Figure 11, we can observed that, as the value of magnetic parameter $M$ increases, the skin friction coefficient $f^{\prime \prime}(0)$ also increases as the magnitude of the suction parameter increases. This is because of the presence of a transverse magnetic field is determined by the Lorentz force, which results in a hindering force in the velocity field, as discussed earlier in Figure 2 until 4. However, as we look at Figure 12 and 13, the variations $g^{\prime}(0)$ and $h^{\prime}(0)$ decrease as the magnitude of the suction and magnetic parameters increase. It is intriguing to point out that, in this study, dual solutions are found to exist infinitely for any value of the parameters considered. As a result, there is an absence in the critical value and the turning point, as opposed to other studies that have managed to obtain multiple solutions for a certain range of parameters. This scenario has been mentioned by Hafidzuddin et al., [31].

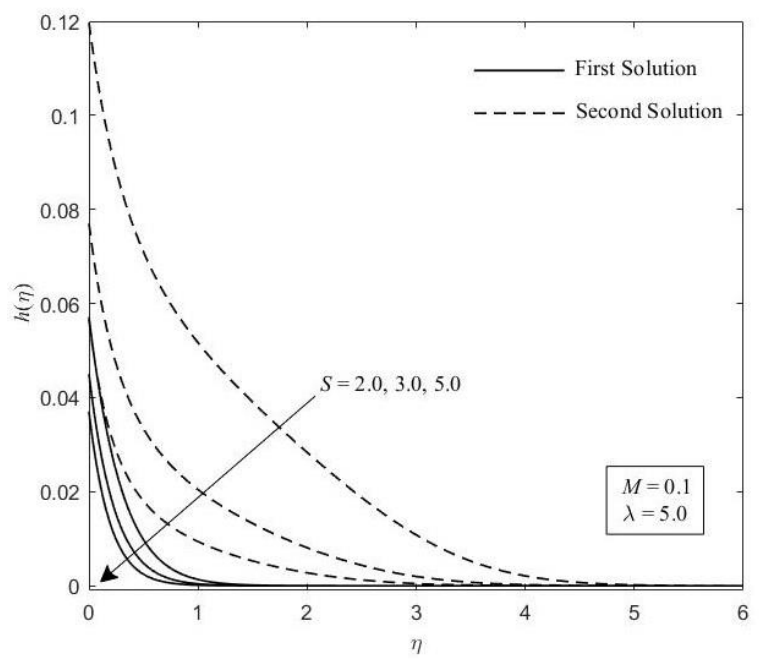

Fig. 10. The velocity profiles $h(\eta)$ for different values of $S$

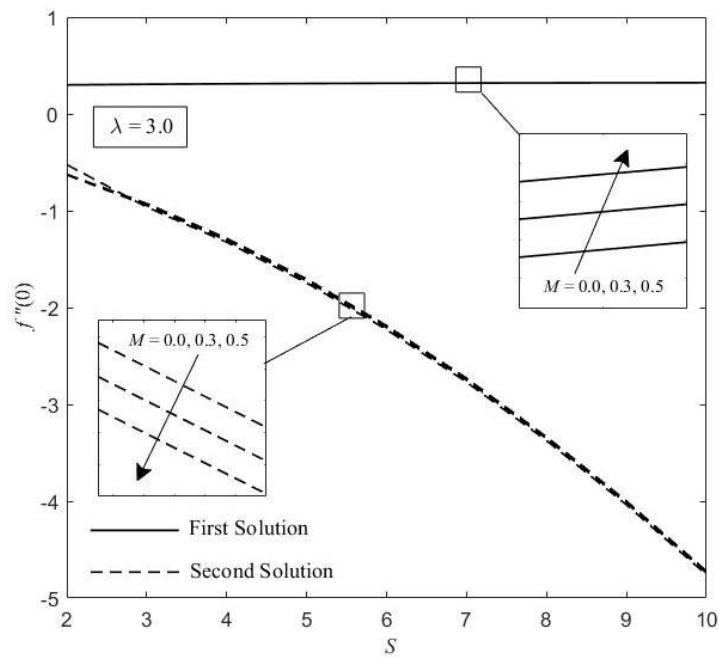

Fig. 11. Variation of the skin friction coefficient $f^{\prime \prime}(0)$ with $S$ for several values of $M$ 


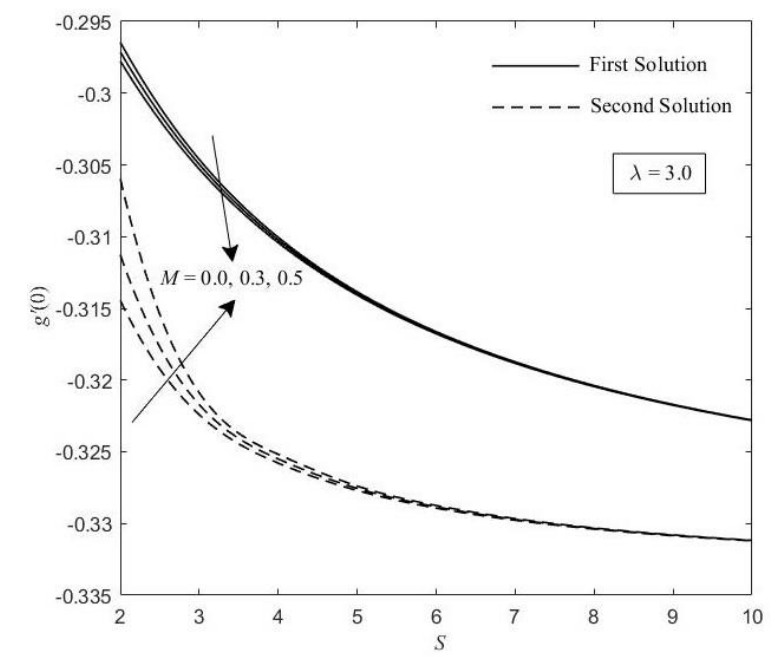

Fig. 12. Variation of the skin friction coefficient $g^{\prime}(0)$ with $S$ for several values of $M$

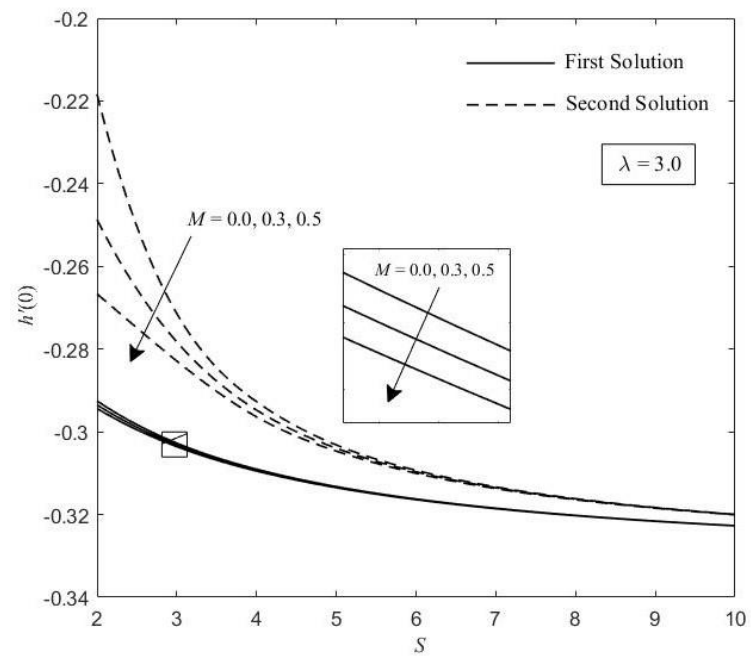

Fig. 13. Variation of the skin friction coefficient $h^{\prime}(0)$ with $S$ for several values of $M$

\section{Conclusions}

The present research deals with the numerical analysis of magnetohydrodynamics (MHD) stagnation slip flow over a permeable plate with suction effect. By using the bvp4c method, the numerical results obtained and compared with the previous published results and a good agreement was found in this study. Based on the results obtained in this study, we can say that the velocity profiles are obtained from the solver with the increasing value of the magnetic, slip and suction parameters. It is found that velocity profile $f^{\prime}(\eta)$ shows increasing behaviour as magnetic, slip and suction parameters increase. In addition, velocity profiles $g(\eta)$ and $h(\eta)$ show decreasing behaviour with the magnetic, slip and suction parameters. This can be concluded that the increasing of magnetic parameter gives increment in the skin friction coefficient. Next, the increasing of suction parameter affect in an increase the skin friction coefficient, which caused the reduction of momentum boundary layer thickness, enhance the flow near the surface of the wall. The dual solutions are found to exist infinitely when suction is implied.

\section{Acknowledgement}

The authors gratefully acknowledge the financial support from Universiti Putra Malaysia in the form of Putra Grant (Project number: GP-IPS/2018/9570000) and Ministry of Higher Education of Malaysia (FRGS Grant FRGS/1/2019/STG06/UPM/02/6).

\section{References}

[1] Mukhopadhyay, Swati, and Iswar Chandra Mandal. "Magnetohydrodynamic (MHD) mixed convection slip flow and heat transfer over a vertical porous plate." Engineering Science and Technology, an International Journal 18, no. 1 (2015): 98-105. https://doi.org/10.1016/i.jestch.2014.10.001

[2] Reza, M., and A. S. Gupta. "MHD stagnation-point flow of an electrically conducting fluid on the surface of another quiescent fluid." Acta Mechanica 223, no. 11 (2012): 2303-2310. https://doi.org/10.1007/s00707-012-0708-y

[3] Ghadikolaei, S. S., M. Yassari, H. Sadeghi, Kh Hosseinzadeh, and D. D. Ganji. "Investigation on thermophysical properties of Tio2-Cu/H2O hybrid nanofluid transport dependent on shape factor in MHD stagnation point flow." Powder technology 322 (2017): 428-438. https://doi.org/10.1016/j.powtec.2017.09.006

[4] Ibrahim, Wubshet. "The effect of induced magnetic field and convective boundary condition on MHD stagnation 
point flow and heat transfer of upper-convected Maxwell fluid in the presence of nanoparticle past a stretching sheet." Propulsion and Power Research 5, no. 2 (2016): 164-175.

https://doi.org/10.1016/i.jppr.2016.05.003

[5] Jalilpour, B., S. Jafarmadar, D. D. Ganji, A. B. Shotorban, and H. Taghavifar. "Heat generation/absorption on MHD stagnation flow of nanofluid towards a porous stretching sheet with prescribed surface heat flux." Journal of Molecular Liquids 195 (2014): 194-204.

https://doi.org/10.1016/i.molliq.2014.02.021

[6] Ali, Fadzilah Md, Roslinda Nazar, Norihan Md Arifin, and loan Pop. "MHD stagnation-point flow and heat transfer towards stretching sheet with induced magnetic field." Applied Mathematics and Mechanics 32, no. 4 (2011): 409-418.

https://doi.org/10.1007/s10483-011-1426-6

[7] Junoh, Mohamad Mustaqim, Fadzilah Md Ali, Norihan Md Arifin, Norfifah Bachok, and loan Pop. "MHD stagnation-point flow and heat transfer past a stretching/shrinking sheet in a hybrid nanofluid with induced magnetic field." International Journal of Numerical Methods for Heat and Fluid Flow 30, no. 3 (2019): 1345-1364. https://doi.org/10.1108/HFF-06-2019-0500

[8] Junoh, Mohamad Mustaqim, Fadzilah Md Ali, and Ioan Pop. "Magnetohydrodynamics stagnation-point flow of a nanofluid past a stretching/shrinking sheet with induced magnetic field: A revised model." Symmetry 11, no. 9 (2019): 1078.

https://doi.org/10.3390/sym11091078

[9] Mandal, Iswar Chandra, and Swati Mukhopadhyay. "MHD combined convective flow and heat transfer past a porous stretching surface embedded in a porous medium." Acta Technica CSAV (Ceskoslovensk Akademie Ved) 57, no. 1 (2012): 17-32.

[10] Zhu, Jing, Liancun Zheng, and Zhi-gang Zhang. "Effects of slip condition on MHD stagnation-point flow over a Power-law stretching sheet." Applied Mathematics and Mechanics 31, no.4 (2010): 439-448.

https://doi.org/10.1007/s10483-010-0404-z

[11] Ellahi, Rahmat, Sultan Z Alamri, Abdul Basit, and A. Majeed. "Effects of MHD and slip on heat transfer boundary layer flow over a moving plate based on specific entropy generation." Journal of Taibah University for Science 12, no. 4 (2018): 476-482.

https://doi.org/10.1080/16583655.2018.1483795

[12] Nandeppanavar, Mahantesh M., M. C. Kemparaju, and S. Shakunthala. "MHD stagnation point slip flow due to a non-linearly moving surface with effect of non-uniform heat source." Nonlinear Engineering 8, no. 1 (2019): 270282.

https://doi.org/10.1515/nleng-2017-0109

[13] Zaimi, Khairy, and Anuar Ishak. "Stagnation-point flow towards a stretching vertical sheet with slip effects." Mathematics 4, no. 2 (2016): 27. https://doi.org/10.3390/math4020027

[14] Bachok, Norfifah, Anuar Ishak, and loan Pop. "Stagnation point flow toward a stretching/shrinking sheet with a convective surface boundary condition." Journal of The Franklin Institute 350, no. 9 (2013): 2736-2744.

https://doi.org/10.1016/j.jfranklin.2013.07.002

[15] Bachok, Norfifah, Anuar Ishak, and Ioan Pop. "MHD flow and heat transfer near the stagnation point on a stretching/shrinking sheet in a micropolar fluid." Magnetohydrodynamics 47, no. 3 (2011): 237-247. https://doi.org/10.22364/mhd.47.3.3

[16] Mukhopadhyay, Swati. "Slip effects on MHD boundary layer flow over an exponentially stretching sheet with suction/blowing and thermal radiation." Ain Shams Engineering Journal 4, no. 3 (2013): 485-491. https://doi.org/10.1016/i.asej.2012.10.007

[17] Khan, Muhammad ljaz, Muhammad Tamoor, Tasawar Hayat, and Ahmed Alsaedi. "MHD boundary layer thermal slip flow by nonlinearly stretching cylinder with suction/blowing and radiation." Results in Physics 7 (2017): 12071211. https://doi.org/10.1016/j.rinp.2017.03.009

[18] Yian, Lok Yian, Anuar Ishak, and loan Pop. "MHD stagnation point flow with suction towards a shrinking sheet." Sains Malaysiana 40, no. 10 (2011): 1179-1186.

[19] Ishak, Anuar, Roslinda Nazar, and loan Pop. "Dual solutions in mixed convection boundary-layer flow with suction or injection." IMA Journal of Applied Mathematics 72, no. 4 (2007): 451-463. https://doi.org/10.1093/imamat/hxm020

[20] Mansur, Syahira, Anuar Ishak, and Ioan Pop. "The Magnetohydrodynamic stagnation point flow of a nanofluid over a stretching/shrinking sheet with suction." PLOS ONE 10, no. 3 (2015): 1-14.

https://doi.org/10.1371/journal.pone.0117733 
[21] Ali, Fadzilah Md, Roslinda Nazar, Norihan Md Arifin, and Ioan Pop. "An MHD stagnation slip flow on a moving plate." Fluid Dynamics Research 43, no. 1 (2011): 015502. https://doi.org/10.1088/0169-5983/43/1/015502

[22] Ali, Fadzilah Md, Roslinda Nazar, Norihan Md Arifin, and loan Pop. "Dual Solutions in MHD Flow on a Nonlinear Porous Shrinking Sheet in a Viscous Fluid." Boundary Value Problems 2013, no. 1 (2013): 32. https://doi.org/10.1186/1687-2770-2013-32

[23] Abdul Hamid, Rohana, Norihan Md Arifin, Roslinda Nazar, Fadzilah Md Ali, and loan Pop. "Dual solutions on thermosolutal Marangoni forced convection boundary layer with suction and injection." Mathematical Problems in Engineering 2011 (2011). https://doi.org/10.1155/2011/875754

[24] Junoh, Mohamad Mustaqim, Fadzilah Md Ali, Norihan Md Arifin, and Norfifah Bachok. "Dual solutions in magnetohydrodynamic (MHD) flow on a nonlinear porous shrinking sheet: A stability analysis." AIP Conference Proceedings 1974 (2018): 020083. https://doi.org/10.1063/1.5041614

[25] Naganthran, Kohilavani, and Roslinda Nazar. "Dual solutions of MHD stagnation-point flow and heat transfer past a stretching/shrinking sheet in a porous medium." AIP Conference Proceedings 1830, no. 1 (2017): 20038. https://doi.org/10.1063/1.4980901

[26] Anuar, Nur Syazana, Norfifah Bachok, and loan Pop. "A stability analysis of solutions in boundary layer flow and heat transfer of carbon nanotubes over a moving plate with slip effect." Energies 11, no. 12 (2018): 3243. https://doi.org/10.3390/en11123243

[27] Aleng, Nur Liyana, Norfifah Bachok, and Norihan Arifin. "Dual solutions of exponentially stretched/shrinked flows of nanofluids." Journal of Nanofluids 7 (2018): 195-202. https://doi.org/10.1166/jon.2018.1425

[28] Ishak, Anuar Roslinda Nazar, Norfifah Bachok, and loan Pop. "MHD mixed convection flow adjacent to a vertical plate with prescribed surface temperature." International Journal of Heat and Mass Transfer 53, no. 21 (2010): 4506-4510. https://doi.org/10.1016/i.ijheatmasstransfer.2010.06.043

[29] Wang, C. Y. "Stagnation slip flow and heat transfer on a moving plate." Chemical Engineering Science 61, no. 23 (2006): 7668-7672. https://doi.org/10.1016/i.ces.2006.09.003

[30] Ariel, P. D. "Hiemenz Flow in Hydromagnetics." Acta Mechanica 103, no. 1 (1994): 31-43. https://doi.org/10.1007/BF01180216

[31] Hafidzuddin, Ezad Hafidz, Roslinda Nazar, Norihan Md Arifin, and Ioan Pop. "Effects of anisotropic slip on threedimensional stagnation-point flow past a permeable moving surface." European Journal of Mechanics - B/Fluids 65, (2017): 515-521.

https://doi.org/10.1016/i.euromechflu.2017.05.011 